\title{
Risk prediction for breast Cancer in Han Chinese women based on a cause-specific Hazard model
}

Lu Wang ${ }^{1 \dagger}$, Liyuan Liü ${ }^{2,3 \dagger}$, Zhen Lou ${ }^{4}$, Lijie Ding ${ }^{5}$, Hui Guan ${ }^{6}$, Fei Wang ${ }^{2,3}$, Lixiang Yu ${ }^{2,3}$, Yujuan Xiang ${ }^{2,3}$,

Fei Zhou ${ }^{2,3}$, Fuzhong $X^{1} e^{1 *}$ and Zhigang $\mathrm{Yu}^{2,3,7^{*}}$ (D)

\begin{abstract}
Background: Considering the lack of efficient breast cancer prediction models suitable for general population screening in China. We aimed to develop a risk prediction model to identify high-risk populations, to help with primary prevention of breast cancer among Han Chinese women.

Methods: A cause-specific competing risk model was used to develop the Han Chinese Breast Cancer Prediction model. Data from the Shandong Case-Control Study (328 cases and 656 controls) and Taixing Prospective Cohort Study (13,176 participants) were used to develop and validate the model. The expected/observed (E/O) ratio and Cstatistic were calculated to evaluate calibration and discriminative accuracy of the model, respectively.

Results: Compared with the reference level, the relative risks (RRs) for highest level of number of abortions, age at first live birth, history of benign breast disease, body mass index (BMI), family history of breast cancer, and life satisfaction scores were $6.3,3.6,4.3,1.9,3.3,2.4$, respectively. The model showed good calibration and discriminatory accuracy with an E/O ratio of 1.03 and C-statistic of 0.64 .
\end{abstract}

Conclusions: We developed a risk prediction model including fertility status and relevant disease history, as well as other modifiable risk factors. The model demonstrated good calibration and discrimination ability.

Keywords: Breast neoplasms, Population at risk, Risk assessment

\section{Background}

Breast cancer is one of the most prevalent malignancies among women worldwide [1]. Although the incidence of breast cancer is low compared with Western countries, China is currently experiencing increasing trends in both breast cancer incidence and mortality [2]. However, the mammography screening participation rate is only $21.7 \%$ in China, far lower than in Western countries [3]. Considering the limited medical resources, especially in rural areas of China, a risk prediction model that is suitable for general population screening is urgently needed.

\footnotetext{
* Correspondence: xuefzh@sdu.edu.cn; yzg@medmail.com.cn

${ }^{\dagger}$ Lu Wang and Liyuan Liu contributed equally to this work.

'Department of Biostatistics, School of Public Health, Shandong University,

44 Wen Hua Xi Road, Jinan 250012, China

${ }^{2}$ Department of Breast Surgery, the Second Hospital of Shandong University, Jinan 250033, China

Full list of author information is available at the end of the article
}

Competing risks are said to be present when an individual is at risk for more than one mutually exclusive event, such as death from a different cause, and the occurrence of one of these competing events will prevent the event of interest from ever happening. A cause-specific hazard model considers competing risks and therefore has better performance than the Cox model when used for disease risk prediction. Gail proposed a method to estimate individual probabilities of developing breast cancer, based on a cause-specific hazard model [4]. Several risk prediction models have been developed in Western countries; the two most widely used are the Gail cause-specific hazard model with traditional risk factors as predictors [4], and the International Breast Cancer Intervention Study (IBIS)model, which includes genetic markers [5]. The Gail II model was developed based on the Gail model and provides a feasible web-based instrument [6]; however, that model was first developed in a Caucasian ethnic

(c) The Author(s). 2019 Open Access This article is distributed under the terms of the Creative Commons Attribution 4.0 International License (http://creativecommons.org/licenses/by/4.0/), which permits unrestricted use, distribution, and reproduction in any medium, provided you give appropriate credit to the original author(s) and the source, provide a link to the Creative Commons license, and indicate if changes were made. The Creative Commons Public Domain Dedication waiver (http://creativecommons.org/publicdomain/zero/1.0/) applies to the data made available in this article, unless otherwise stated. 
population so the effects maybe uncertain when directly applied to Han Chinese women [4, 6-11]. Moreover, because biopsies are not widely used in China (especially in rural areas), information on the number of previous breast biopsies is not readily available for most Chinese women. Although other prediction models include genetic risk prediction models such as the IBIS model [12], their higher cost may lead to limited application considering the large population in China. In addition, the most important genetic factor of breast cancer, the $B R C A$ gene mutation rate, is lower in the Chinese population than those in Western countries [13]. The aim of our study was to develop a breast cancer risk prediction model using non-laboratory indicators in a population of Han Chinese women, and to convert the model into a simple tool that can be conveniently used in clinical and public health practice.

\section{Methods}

\section{Study population}

All participants were selected from the study population of the project "Ministry-affiliated Hospital Key Project of the Ministry of Health of the People's Republic of China (No. 07090122)". We conducted a population-based case-control study in Shandong Province to develop the prediction model, which was then validated in the Taixing Prospective Cohort Study. The study protocol was approved by Shandong University and informed consent was obtained from all study participants.

In the population-based Shandong Case-Control Study, which was conducted from 2008 to 2012, the target population included 25- to 70-year-old women of Han ethnicity, with over 2 years of local residence and at least 6 months of local residence at the time of the survey. Breast cancer patients were from the department of breast surgery at the Second Hospital of Shandong University. All patients were newly diagnosed with breast cancer. Each eligible patient who had been pathologically diagnosed with breast cancer was matched with two healthy controls according to age ( \pm 2 years) and location (neighbor or co-worker in the same region). Finally, 328 cases and 656 controls were included in the Shandong Case-Control Study. Details of the questionnaire used in this study are described elsewhere [2, 14].

In the Taixing Prospective Cohort Study, 18,681 participants who completed a questionnaire in 2008 were included as the baseline population, and outcomes were collected after 7 years of follow-up. Participants who have not been diagnosed with breast cancer at baseline were selected for the study $(n=18,657)$, after excluding participants with missing data of risk factors $(n=116)$. Among 18,541 eligible participants, 5365 participants were lost to follow-up. The rate of lost to follow-up was 28.9\% (owing to adjustment of the administrative jurisdiction, one township was excluded from Taixing City when collecting follow-up information). Finally, 13,176 individuals were enrolled. New incident cases of breast cancer were identified from local cancer registries and via active follow-up telephone and face-to-face interviews. The flow chart of the enrollment in these two studies was shown in Fig. 1.

\section{Measurements and definition of risk factors}

A self-designed structured questionnaire that included demographic characteristics, female physiological and reproductive factors, medical and family history, dietary habits, lifestyle habits, and breast-cancer-related knowledge was used to obtain data [2]. Data were collected via in-person interviews. Body mass index (BMI) was calculated as weight in kilograms divided by height in meters squared; BMI was divided into $<24,24-27.9, \geq 28$ corresponding to normal weight, overweight, and obesity [15]. Height was measured using a meter rule with a precision of $0.1 \mathrm{~cm}$, and weight was measured using an electronic weight scale with an accuracy of $0.1 \mathrm{~kg}$. Life satisfaction scores (with respect to housing, income, health, marriage, medical care, and neighbors) were measured using 1/2/3/4/5 scale where 1 is very satisfied and 5 is very unsatisfied. A total point of 30 was divided into two levels by the mean value 13 , people with scores lower than 13 were defined as satisfied and scores $\geq 13$ were defined as unsatisfied. A positive breast cancer family history was defined as any first-, second-, or third-degree relative with a diagnosis of breast cancer. Information on the number of abortions, age at first live birth, and history of benign breast disease were also collected using the questionnaire. All of the above variables have been reported as potential risk factors of developing breast cancer. The coding for the six risk factors is shown in Table 1.

\section{Statistical methods}

To project individual probabilities (absolute risks) of developing breast cancer, we applied the cause-specific hazard model approach [4], according to the following steps.

(1) We estimated the relative risks (RRs) and attributable risk (AR) in the Shandong Case-Control Study.

To estimate RRs, odds ratios (ORs) and the corresponding 95\% confidence intervals (CIs) were calculated in conditional logistic regression for matched data using the above variables and coding, as described in Table 1. Variable selection for inclusion in the final model was based on Wald tests for individual parameters as well as information on previously established risk factors. To estimate the AR, we applied Bruzzi's method [16]. The AR was estimated using the Taixing cohort and was applied to Taixing City only.

(2) We calculated age-specific baseline hazards for breast cancer (based on the breast cancer incidence rate of the Cancer Surveillance System of the Taixing Centers for Disease Control) and for competing events (based on 
Table 1 Characteristics of the Shandong Case-Control Study and baseline characteristics of the Taixing Prospective Cohort Study

\begin{tabular}{|c|c|c|c|c|c|c|c|c|}
\hline \multirow[t]{2}{*}{ Variables } & & \multirow[t]{2}{*}{ Code } & \multicolumn{3}{|c|}{ Shandong Case Control Study } & \multicolumn{3}{|c|}{ Taixing Prospective Cohort Study } \\
\hline & & & case $(n=328)$ & $\operatorname{control}(n=656)$ & $P$-value & case $(n=34)$ & $\operatorname{control}(n=13,142)$ & $P$-value \\
\hline Age & Year & & $49.65 \pm 9.26$ & $49.65 \pm 9.26$ & 0.992 & $47.06 \pm 9.45$ & $46.78 \pm 11.46$ & 0.888 \\
\hline \multirow[t]{3}{*}{ Number of abortions } & 0 & 0 & $137(41.77)$ & $460(70.12)$ & & $23(67.65)$ & $9612(73.14)$ & \\
\hline & $1-2$ & 1 & $164(50.00)$ & $177(26.98)$ & $<0.001$ & $10(29.41)$ & $3210(24.43)$ & 0.771 \\
\hline & $\geq 3$ & 2 & $27(8.23)$ & $19(2.90)$ & & $1(2.94)$ & $320(2.43)$ & \\
\hline \multirow[t]{3}{*}{ Age at first live birth } & $<25$ & 0 & $128(39.02)$ & $378(57.62)$ & & $23(67.65)$ & $9853(74.97)$ & \\
\hline & $25-29$ & 1 & $175(53.35)$ & $253(38.57)$ & $<0.001$ & $11(32.35)$ & $3138(23.88)$ & 0.438 \\
\hline & $\geq 30$ & 2 & $25(7.62)$ & $25(3.81)$ & & $0(0.00)$ & $151(1.15)$ & \\
\hline $\begin{array}{l}\text { Benign breast disease } \\
\text { history }\end{array}$ & Yes & 1 & $18(5.49)$ & $7(1.07)$ & $<0.001$ & $0(0.00)$ & $46(0.35)$ & 1.000 \\
\hline \multirow[t]{3}{*}{ BMl } & $<24$ & 0 & $143(43.60)$ & $347(52.90)$ & & $17(50.00)$ & 9039 (68.78) & \\
\hline & $24-27.9$ & 1 & $130(39.63)$ & $233(35.52)$ & 0.002 & $14(41.18)$ & $3690(28.08)$ & 0.026 \\
\hline & $\geq 28$ & 2 & $55(16.77)$ & $76(11.59)$ & & $3(8.82)$ & $413(3.14)$ & \\
\hline Breast cancer family history & Yes & 1 & $19(5.79)$ & $9(1.37)$ & $<0.001$ & $2(5.88)$ & $90(0.68)$ & 0.009 \\
\hline Life satisfaction scores & $\geq 13$ & 1 & $188(57.32)$ & $229(34.91)$ & $<0.001$ & $22(64.71)$ & $6907(52.56)$ & 0.213 \\
\hline
\end{tabular}

*Data are mean \pm SD and frequency (percent) for numeric and discrete variables

non-breast cancer mortality from the Death Surveillance System of the Taixing Centers for Disease Control).

Twelve age groups were defined (ranges 25-29, 30-34, $35-39,40-44,45-49,50-54,55-59,60-64,65-69,70-$ $74,75-79,80-84$ years). The baseline hazard was defined as the hazard rate for each individual whose risk factors were at the lowest risk level. The baseline hazards of breast cancer were estimated by multiplying the age-specific breast cancer incidence rates by $(1-$ estimated population AR).
(3) We combined baseline hazards (for breast cancer and competing events) and RRs to estimate probabilities in the developed Han Chinese Breast Cancer Prediction (HCBCP) model. The absolute risks were calculated according to initial age, follow-up duration, and initial RRs in the HCBCP model. A simple computing method for individualized risk assessment was performed [17].

(4) Finally, the Taixing Prospective Cohort Study was used to validate the HCBCP model. We used E/O ratios (which are defined as the observed divided by the expected

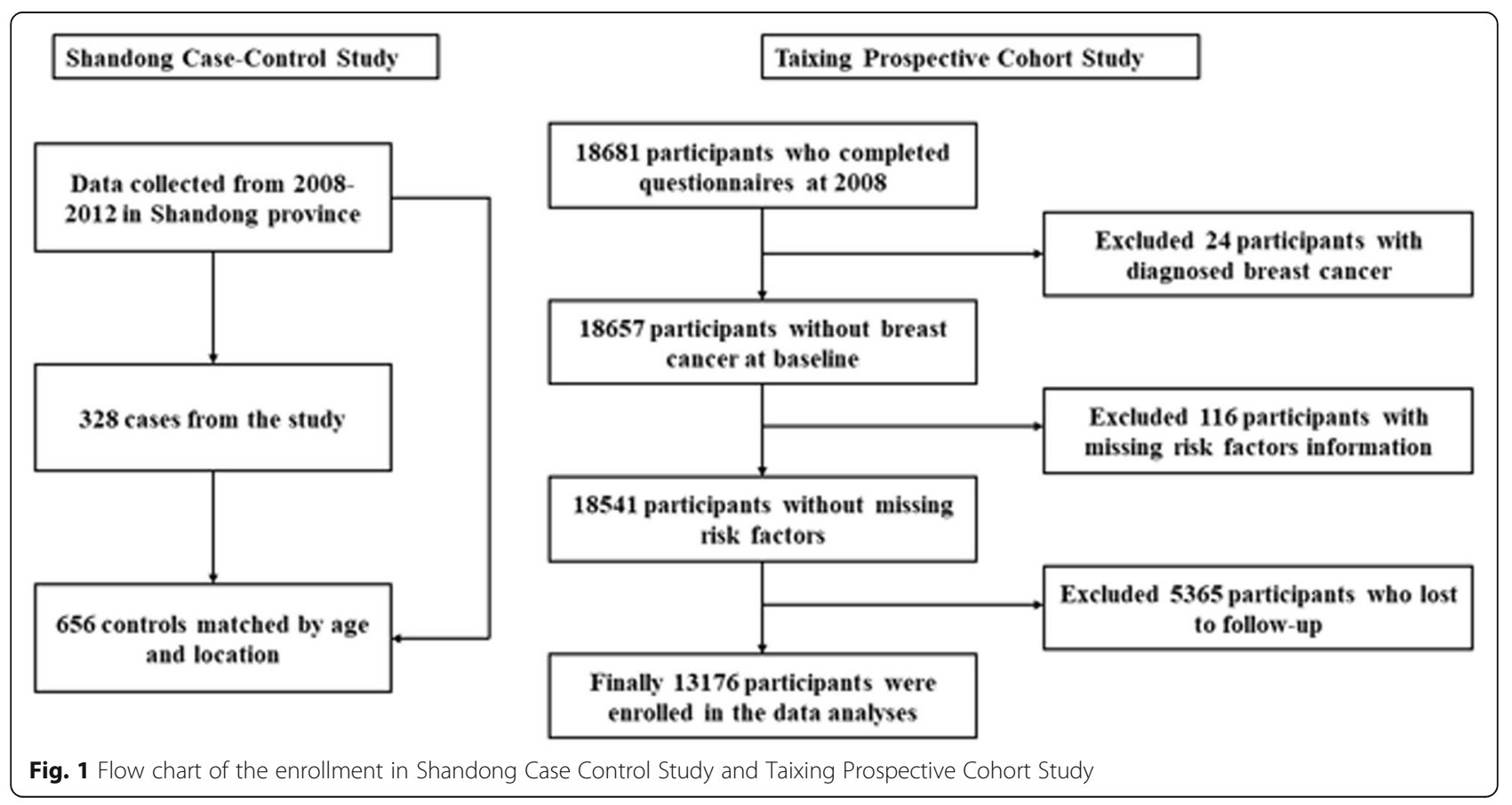


number, with a number close to 1 showing good model fit) to assess model calibration. The $\mathrm{C}$-statistic, which is the probability that a randomly chosen positive instance will rank higher than a randomly chosen negative one, was used to evaluate the model's discriminatory ability.

SAS version 9.4 (SAS Institute Inc., Cary, NC, USA) was used to perform data cleaning and to calculate RRs. We used R (The R Project for Statistical Computing, Vienna, Austria) to develop the HCBCP model; the corresponding code is provided in Additional file 1.

\section{Results}

\section{Relative and attributable risks in the Shandong case-control study}

Table 1 shows the characteristics of the Shandong CaseControl Study and baseline characteristics of the Taixing Prospective Cohort Study by breast cancer. The average age of participants in these studies was 49.6 and 49.65 years for those with and without breast cancer, respectively, in the Shandong Case-Control Study, and 47.06 and 46.78 years for those with and without breast cancer, respectively, in the Taixing Prospective Cohort Study.

RRs were estimated using multivariate conditional logistic regression. Risk factors that were significant in univariate ordered logistic regression (see Additional file 2: Table S1) and multivariable logistic regression were included in the final model. Diabetes was a risk factor in univariate logistic regression but was not significant after multivariate-adjustment; therefore, it was not included in the final risk model. Table 2 summarizes the RR of each risk factor. Compared with the reference level, the RRs (95\% CI) for a highest level of number of abortions, age at first live birth, benign breast disease history, BMI, family history of breast cancer, and life satisfaction score were 6.313 (4.792, 8.316), 3.589 (2.747, 4.690), 4.255 (1.613, 11.229), 1.882 (1.503, 2.356), 3.250 (1.339, $7.890)$, and 2.424 (1.777, 3.308), respectively. For breast cancer family history, in about $8.9 \%$ of women with a positive family history was contributed from third-degree relative; the prevalence of breast cancer among third-degree relatives was 62/100,000. RRs for each participant were obtained by multiplying each risk factor's relative risk. The estimated AR was 0.78 .

\section{Individualized absolute risk projections in Taixing prospective cohort study}

The age-specific breast cancer incidence rates and nonbreast cancer mortality rates in Taixing were shown in Additional file 3: Table S2. Table 3 gave 5 to 30 years absolute risk probabilities predicted using the HCBCP model, based on different initial ages and RRs.

For instance, we calculated the 20-year breast cancer risk for a 30-year old woman with a history of one abortion (code $=1)$, who was age 27 years at the first live birth $($ code $=1)$, no history of benign breast disease (code $=0)$, BMI of 27 (code $=1)$, with a family history of breast cancer $($ code $=1)$ and life satisfaction score of 7 (code $=0$ ); the $\mathrm{RR}$ is derived as $2.512 \times 1.895 \times 1 \times$ $1.372 \times 3.250 \times 1=21.23$. Thus, in this example, the 20 -year absolute risk would be $2.71 \%$ with RR of 20.0 (Table 3). The approximation was obtained as: 2.71 + (3.38-2.71) (21.23-20.00)/(25-20) $=2.87 \%$, which means this woman has a $2.87 \%$ probability of developing breast cancer in the next 20 years. The approximation probability was close to the exact calculation of $2.88 \%$.

Table 2 Relative risks estimated using multivariate logistic regression for the Shandong Case-Control Study

\begin{tabular}{|c|c|c|c|c|c|c|}
\hline \multicolumn{2}{|l|}{ Variables } & \multirow{2}{*}{$\begin{array}{l}\text { Code } \\
0\end{array}$} & \multirow{2}{*}{$\begin{array}{l}\mathrm{RR} \\
1.000\end{array}$} & \multicolumn{2}{|l|}{$95 \% \mathrm{Cl}$} & \multirow[t]{2}{*}{$P$-value } \\
\hline Number of abortions & 0 & & & - & & \\
\hline & $1-2$ & 1 & 2.512 & 1.907 & 3.310 & $<0.001$ \\
\hline & $\geq 3$ & 2 & 6.313 & 4.792 & 8.316 & \\
\hline \multirow[t]{3}{*}{ Age at first live birth } & $<25$ & 0 & 1.000 & - & & $<0.001$ \\
\hline & $25-29$ & 1 & 1.895 & 1.45 & 2.475 & \\
\hline & $\geq 30$ & 2 & 3.589 & 2.747 & 4.690 & \\
\hline \multirow[t]{2}{*}{ Benign breast disease history } & No & 0 & 1.000 & - & & 0.003 \\
\hline & Yes & 1 & 4.255 & 1.613 & 11.229 & \\
\hline \multirow[t]{3}{*}{ BMI } & $<24$ & 0 & 1.000 & - & & 0.006 \\
\hline & $24-27.9$ & 1 & 1.372 & 1.096 & 1.717 & \\
\hline & $\geq 28$ & 2 & 1.882 & 1.503 & 2.356 & \\
\hline \multirow[t]{2}{*}{ Breast cancer family history } & No & 0 & 1.000 & - & & 0.009 \\
\hline & Yes & 1 & 3.250 & 1.339 & 7.890 & \\
\hline \multirow[t]{2}{*}{ Life satisfaction scores } & $<13$ & 0 & 1.000 & - & & $<0.001$ \\
\hline & $\geq 13$ & 1 & 2.424 & 1.777 & 3.308 & \\
\hline
\end{tabular}


Table 3 Projected absolute risk (\%) of breast cancer by relative risks, initial age, and follow-up years

\begin{tabular}{|c|c|c|c|c|c|c|c|}
\hline \multirow{3}{*}{$\begin{array}{l}\text { Initial } \\
\text { age,y }\end{array}$} & \multirow{3}{*}{$\begin{array}{l}\text { follow-up } \\
\text { years }\end{array}$} & \multicolumn{6}{|c|}{ Projected absolute risk, \% } \\
\hline & & \multicolumn{6}{|c|}{ Relative risk } \\
\hline & & 1 & 5 & 10 & 15 & 20 & 25 \\
\hline \multirow[t]{3}{*}{25} & 10 & 0.01 & 0.03 & 0.06 & 0.09 & 0.12 & 0.15 \\
\hline & 20 & 0.07 & 0.36 & 0.71 & 1.06 & 1.42 & 1.77 \\
\hline & 30 & 0.18 & 0.88 & 1.74 & 2.60 & 3.46 & 4.30 \\
\hline \multirow[t]{4}{*}{30} & 5 & 0.01 & 0.03 & 0.06 & 0.09 & 0.12 & 0.15 \\
\hline & 10 & 0.01 & 0.06 & 0.11 & 0.17 & 0.22 & 0.28 \\
\hline & 20 & 0.14 & 0.69 & 1.37 & 2.04 & 2.71 & 3.38 \\
\hline & 30 & 0.22 & 1.09 & 2.16 & 3.22 & 4.27 & 5.31 \\
\hline \multirow[t]{4}{*}{40} & 5 & 0.06 & 0.30 & 0.60 & 0.91 & 1.20 & 1.50 \\
\hline & 10 & 0.13 & 0.63 & 1.26 & 1.89 & 2.51 & 3.13 \\
\hline & 20 & 0.21 & 1.04 & 2.06 & 3.08 & 4.08 & 5.08 \\
\hline & 30 & 0.28 & 1.39 & 2.76 & 4.10 & 5.43 & 6.74 \\
\hline \multirow[t]{4}{*}{50} & 5 & 0.04 & 0.20 & 0.40 & 0.60 & 0.80 & 0.99 \\
\hline & 10 & 0.08 & 0.42 & 0.83 & 1.24 & 1.65 & 2.06 \\
\hline & 20 & 0.16 & 0.78 & 1.55 & 2.31 & 3.07 & 3.82 \\
\hline & 30 & 0.20 & 1.01 & 2.01 & 3.00 & 3.99 & 4.96 \\
\hline \multirow[t]{3}{*}{60} & 5 & 0.04 & 0.20 & 0.41 & 0.61 & 0.81 & 1.01 \\
\hline & 10 & 0.08 & 0.38 & 0.76 & 1.13 & 1.51 & 1.88 \\
\hline & 20 & 0.13 & 0.63 & 1.25 & 1.87 & 2.48 & 3.09 \\
\hline \multirow[t]{2}{*}{70} & 5 & 0.01 & 0.07 & 0.14 & 0.21 & 0.28 & 0.35 \\
\hline & 10 & 0.06 & 0.28 & 0.55 & 0.83 & 1.10 & 1.38 \\
\hline
\end{tabular}

Evaluation of the HCBCP model in the Taixing prospective cohort study

In the Taixing Prospective Cohort Study, among 13,176 individuals who were breast cancer free at baseline, 34 had developed breast cancer after 7 years of follow-up. The incidence rate was $36.86 / 100,000$ person-years.

The model calibration was assessed using the E/O ratio in the Taixing Prospective Cohort Study. The E/O ratio and 95\% CI was $1.03(0.74,1.49)$. Receiver operating characteristic (ROC) curve analysis was performed to evaluate the discrimination ability of the HCBCP model. Figure 2 shows the results of ROC analysis to predict the absolute risk of breast cancer using the HCBCP model. The C-statistic was 0.64 (95\% CI: 0.55, 0.72) with standard error 0.044 .

\section{Comparison with other models}

We compared the HCBCP model with the Gail model in the Taixing Prospective Cohort Study. Owing to a lack of information for the number of biopsies and biopsy atypical hyperplasia among study participants, these predictors were marked as unknown. The $\mathrm{E} / \mathrm{O}$ ratio and 95\% CI was $2.39(1.71,3.46)$, and the C-statistic was 0.54 (95\% CI: 0.44, 0.63). The results showed that the Gail

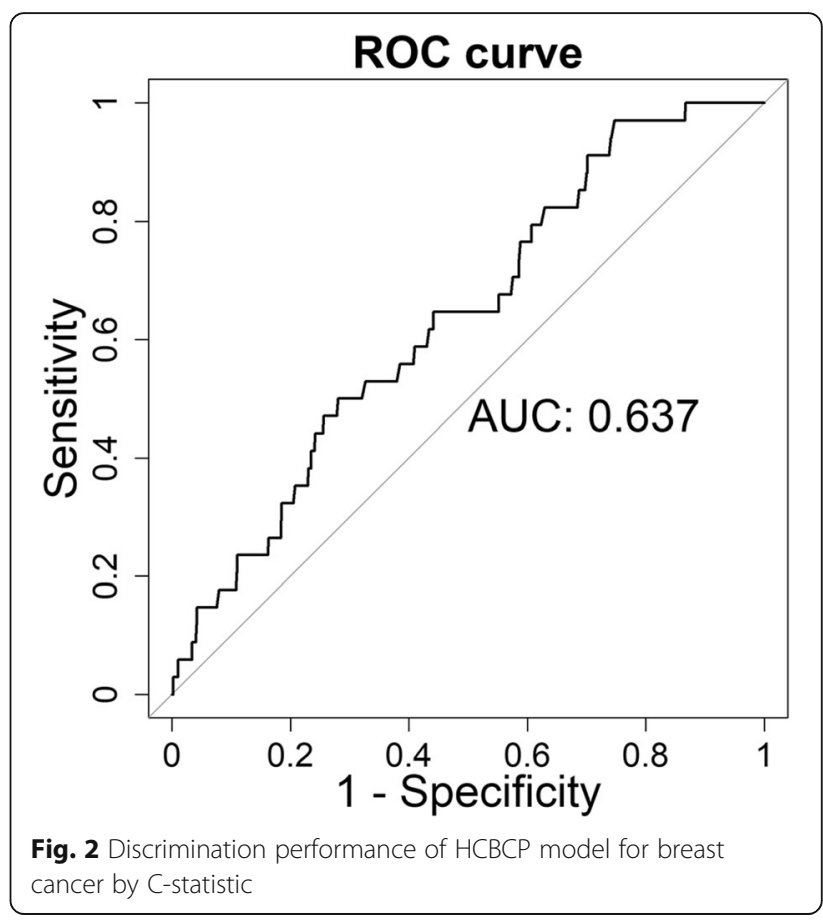

model tended to overestimate the absolute risks in the Taixing cohort. The Health risk appraisal (HRA) model [18], a risk assessment tool for breast cancer prediction among Chinese women, was also applied in the Taixing cohort; the E/O ratio was 1.88 (95\% CI: 1.33, 2.75) and the C-statistic was 0.52 (95\% CI: 0.43, 0.61).

\section{Discussion}

We developed a risk prediction model for breast cancer for use in Han Chinese women. The results of validation showed good calibration and discriminative ability, with E/O ratio 1.03, and C-statistic 0.64 (95\% CI: 0.55, 0.72). Using this model, women with a high risk of developing breast cancer can be identified using simple data collection. With the model, women identified as having high risk can be selected for further breast cancer-related examination, such as mammographic screening. Consequently, there is greater likelihood of identifying women with early-stage breast cancer. Women with higher risk might be motivated to maintain their current health status and take measures to prevent or delay the onset of breast cancer.

Competing risk is commonly existing in disease risk prediction. Traditional survival analysis models (like the Cox model) treat deaths from competing causes as independent censoring events. Hence, bias would be induced into risk prediction [19]. The proportional cause-specific hazard model is commonly used to analyze competing risks. The model computes absolute risk without assuming that these deaths act as "independent censoring" [19]. Therefore, we proposed a cause-specific hazard model to 
estimate absolute risk of an individual for the development of breast cancer.

Selection of the risk factors included in the current model was based on a systematic review of epidemiological studies as well as statistical analyses. In this study, we assessed a variety of factors that are considered to be associated with breast cancer including: number of abortions, age at first live birth, benign breast disease history, $\mathrm{BMI}$, diabetes, breast cancer family history, and life satisfaction score; most risk factors have been confirmed in previous studies.

The relationship between diabetes and breast cancer is controversial. In our study, diabetes was a risk factor in univariate logistic regression (Additional file 2: Table S1) but it was not significant after multivariate-adjustment. This might be owing to the correlation between BMI and diabetes. Obesity is a major risk factor of diabetes. Weight-loss programs can lead to successful long-term weight loss and a decrease in the onset of diabetes [20,21]. BMI has been found to be positively associated with increased risk of diabetes onset [22, 23]. Among women with gestational diabetes mellitus, BMI is significantly and positively associated with risk of progression from gestational diabetes mellitus to type 2 diabetes [24, 25]. However, in a meta-analysis, type 2 diabetes was found to increase the risk of breast cancer by $16 \%$ after adjustment for BMI [26]. One hypothesis is that hyperinsulinemia, as a potential risk factor of breast cancer and a marker of insulin resistance in obesity and type 2 diabetes, may account for the association among BMI, diabetes, and breast cancer [27-29]. Some studies have reported that increased BMI is associated with increased insulin [30]; therefore, BMI may be a confounding factor of diabetes and breast cancer. Compared with the model including diabetes, the model without diabetes showed a change in the $\mathrm{E} / \mathrm{O}$ ratio from 0.99 to 1.03 as well as in the C-statistic, from 0.642 to 0.637 ; the $95 \% \mathrm{CI}$ of the C-statistic also varied from $0.56-0.73$ to $0.55-0.72$ ), as did the standard error (from 0.043 to 0.044 ). Although the inclusion of diabetes in the final risk prediction model increased the C-statistic by 0.005 , it was not significant in multivariate regression and the increase in discrimination was not distinct; thus, we did not include diabetes in the final model.

Life satisfaction scores have not been used in previous breast cancer prediction models. Many articles have reported that negative life events, depression, anxiety, and other harmful psychological and mental factors are related to breast cancer [31-33]. In our results, life satisfaction score showed a significance difference in both univariate and multivariate logistic regression. Life satisfaction status is a modifiable risk factor for which specific prevention measures can be implemented, which is important in community prevention of breast cancer.
Although additional nutrient variables including intakes of calcium, soy products, and iron have been related to breast cancer risk in some studies [34-36], a detailed dietary assessment and supporting nutritional database would be needed to accurately capture nutritional intake, making such assessment unfeasible in most clinical settings. Therefore, we did not include dietary variables that require a detailed assessment.

In China, some studies have added genetic markers to prediction models, to improve discriminative accuracy. Several prediction models have been developed that include some genetic markers and limited environmental predictors, with discriminative accuracy of around 0.6 $[18,37]$. Together with the high cost of testing for genetic markers and the need to obtain blood samples, it is very difficult to implement such risk prediction tools among the general population of China.

In our developed model, all included risk factors are simple and feasible to measure, which improves its convenience and lowers the cost of implementation in a large population. In Western countries, the Gail model is used widely in clinic decision-making [38]. However, application of the Gail model in China is limited because biopsy tests are uncommon. Moreover, several validation studies have been conducted in Asian populations and have reported poor performance of the Gail model [39]. In a comparison with the Gail model in which race was defined as Chinese-American, the predicted incidence rate may still be higher than the actual rate in Taixing. Considering the lack of risk predictors and lower incidence rate in Taixing, Gail model's prediction accuracy may be biased. In China, Yuan et al. developed a risk assessment tool for breast cancer prediction among Chinese women. Although that model's C-statistic was 0.64 (95\% CI: $0.50,0.78)$, the authors included patients from a breast cancer database with data obtained in first-round screening only, with no further follow-up; these data may not be appropriate to test the reliability of the model [18]. In our study, the results of comparison showed that without including competing risks in the prediction model, the HRA model seemed to overestimate the probability of developing breast cancer in the Taixing cohort study. In our validation cohort, the $\mathrm{E} / \mathrm{O}$ ratio was near 1 and showed good projection.

The strength of this study is we developed a simple and efficient prediction model with good calibration and discrimination. The E/O ratio was 1.03 , which is very close to 1 . The $\mathrm{C}$-statistic was 0.64 , which showed that the HCBCP model performed well in the validation study. Modifiable risk factors were selected, such that intervention measures can be carried out in high-risk groups. Using this model, populations at risk can easily be screened, to identify those with increased risk who would benefit from health management advice, to avoid or delay the onset of breast cancer. 
There were also some limitations in our study. First, gene markers were not included in this model, which would lead to a decrease in the discriminative power. Second, we conducted the model using the age-specific breast cancer incidence rate and non-breast cancer mortality rate in Taixing; therefore, application of this HCBCP model may vary by geographic region. Third, the number of incident cases in the Taixing study was small $(n=34)$; therefore, the precision of the validation estimates may be affected. Fourth, owing to the administrative jurisdiction, the rate of loss to follow-up in the validation study was high and may bias the results. Hence, further studies in other areas of China are needed, to validate the performance of this model.

\section{Conclusions}

In conclusion, we developed a risk prediction model including fertility status and relevant disease history as well as other modifiable risk factors. The developed model demonstrated good discriminative accuracy. We expect that the newly developed model can be used to screen populations with a high risk of breast cancer and will contribute to primary and secondary prevention of breast cancer in China.

\section{Additional files}

\section{Additional file 1: $\mathrm{R}$ code for HCBCP model. $\mathrm{R}$ code using to perform} HCBCP model (DOCX 20 kb)

Additional file 2: Table S1. Relative Risk (RR) and 95\% confidence interval $(95 \% \mathrm{Cl})$ of risk factors associated with breast cancer by univariate conditional logistic regression in Shandong Case Control Study (DOCX $15 \mathrm{~kb}$ )

Additional file 3: Table S2. The age-specific breast cancer incidence rates and non-breast cancer mortality rates of Taixing in 2015 (DOCX 14 kb)

Additional file 4: Questionnaire. An English language version of the questionnaire used in this study (PDF $84 \mathrm{~kb}$ )

\section{Abbreviations}

AR: Attributable risk; BMl: Body mass index; HCBCP model: Han Chinese Breast Cancer Prediction model; ORs: Odds ratios; ROC: Receiver Operating Characteristic; RRs: Relative risks

\section{Acknowledgments}

We would like to thank all the subjects involved in the study for their participation. We thank Analisa Avila, ELS, of Liwen Bianji, Edanz Group China (www.liwenbianji.cn/ac), for editing the English text of a draft of this manuscript.

\section{Funding}

This research was primarily granted funding from National Natural Science Foundation of China (No:81602912) and the Science and Technology Plan Projects of Jiangsu Province (No: BL2014055). The funding bodies provided the means to perform the study but had no role in the design of the study, or the collecting, analyzing or interpretation of the data and writing of the manuscript.

\section{Availability of data and materials}

The datasets used and/or analyzed during the current study are available from the corresponding author on reasonable request. An English language version of the questionnaire was provided as Additional file 4.

\section{Authors' contributions}

ZY and FX conceptualized the study, LW and LL analyzed the data and wrote the draft of the manuscript. ZL, LD, HG, FW, LY, YX and FZ substantially contributed to the line of argumentation and revision of the manuscript. All authors read and approved the final manuscript.

\section{Ethics approval and consent to participate}

This study was approved by the institutional review board of Shandong

University. Every patient provided written informed consent before enrollment.

\section{Consent for publication}

Not applicable.

\section{Competing interests}

The authors declare that there were no conflicts of interests.

\section{Publisher's Note}

Springer Nature remains neutral with regard to jurisdictional claims in published maps and institutional affiliations.

\section{Author details}

${ }^{1}$ Department of Biostatistics, School of Public Health, Shandong University, 44 Wen Hua Xi Road, Jinan 250012, China. '2Department of Breast Surgery, the Second Hospital of Shandong University, Jinan 250033, China. ${ }^{3}$ Institute of Translational Medicine of Breast Disease Prevention and Treatment, Shandong University, Jinan 250033, China. ${ }^{4}$ Shandong University of Finance and Economics, Jinan 250014, China. ${ }^{5}$ Division of Health Management, School of Sport Social Science, Shandong Sport University, Jinan 250102, China. 'Department of Radiotherapy, Fourth People's Hospital of Jinan, No 50 Shifan Road, Jinan 250031, Shangdong, China. ${ }^{7}$ Suzhou Institute of Shandong University, Suzhou 215123, China.

Received: 19 July 2018 Accepted: 25 January 2019

Published online: 07 February 2019

\section{References}

1. Torre LA, Bray F, Siegel RL, Ferlay J, Lortet-Tieulent J, Jemal A. Global cancer statistics, 2012. CA Cancer J Clin. 2015:65:87-108.

2. Yu ZG, Jia CX, Liu LY, Geng CZ, Tang JH, Zhang J, et al. The prevalence and correlates of breast cancer among women in eastern China. PLoS One. 2012;7:e37784.

3. Wang B, He M, Wang L, Engelgau MM, Zhao W, Wang L. Breast cancer screening among adult women in China, 2010. Prev Chronic Dis. 2013;10:E183.

4. Gail MH, Brinton LA, Byar DP, Corle DK, Green SB, Schairer C, et al. Projecting individualized probabilities of developing breast cancer for white females who are being examined annually. J Natl Cancer Inst. 1989;81:1879-86.

5. Cuzick J, Forbes J, Edwards R, Baum M, Cawthorn S, Coates A, et al. First results from the international breast Cancer intervention study (IBIS-I): a randomised prevention trial. Lancet. 2002;360:817-24.

6. Costantino JP, Gail MH, Pee D, Anderson S, Redmond CK, Benichou J, et al. Validation studies for models projecting the risk of invasive and total breast cancer incidence. J Natl Cancer Inst. 1999:91:1541-8.

7. Rockhill B, Spiegelman D, Byrne C, Hunter DJ, Colditz GA. Validation of the Gail et al. model of breast cancer risk prediction and implications for chemoprevention. J Natl Cancer Inst. 2001.

8. Kaur JS, Roubidoux MA, Sloan J, Novotny P. Can the Gail model be useful in American Indian and Alaska native populations? Cancer. 2004.

9. Novotny J, Pecen L, Petruzelka L, Svobodnik A, Dusek L, Danes J, et al. Breast cancer risk assessment in the Czech female population - an adjustment of the original Gail model. Breast Cancer Res Treat. 2006.

10. Boyle P, Mezzetti M, La Vecchia C, Franceschi S, Decarli A, Robertson C. Contribution of three components to individual cancer risk predicting breast cancer risk in Italy. Eur J Cancer Prev. 2004.

11. Gao F, Machin D, Chow KY, Sim YF, Duffy SW, Matchar DB, et al. Assessing risk of breast cancer in an ethnically South-East Asia population (results of a multiple ethnic groups study). BMC Cancer. 2012.

12. Tyrer J, Duffy SW, Cuzick J. A breast cancer prediction model incorporating familial and personal risk factors. Stat Med. 2004;23:1111-30.

13. Cao W, Wang X, Li JC. Hereditary breast cancer in the Han Chinese population. J Epidemiol. 2013;23:75-84. 
14. Wang F, Yu L, Wang F, Liu L, Guo M, Gao D, et al. Risk factors for breast cancer in women residing in urban and rural areas of eastern China. J Int Med Res. 2015:43:774-89.

15. Zhou B. Predictive values of body mass index and waist circumference to risk factors of related diseases in Chinese adult population. Zhonghua Liu Xing Bing Xue Za Zhi. 2002;23:5-10.

16. Bruzzi P, Green SB, Byar DP, Brinton LA, Schairer C. Estimating the population attributable risk for multiple risk factors using case-control data. Am J Epidemiol. 1985;122:904-14.

17. Gail MH, Costantino JP, Pee D, Bondy M, Newman L, Selvan M, et al. Projecting individualized absolute invasive breast cancer risk in African American women. J Natl Cancer Inst. 2007;99:1782-92.

18. Wang Y, Gao Y, Battsend M, Chen K, Lu W, Wang Y. Development of a risk assessment tool for projecting individualized probabilities of developing breast cancer for Chinese women. Tumour Biol. 2014;35:10861-9.

19. Gail MH. Personalized estimates of breast cancer risk in clinical practice and public health. Stat Med. 2011:30:1090-104

20. Norris Susan L, Zhang X, Avenell A, Gregg E, Brown T, Schmid Christopher $\mathrm{H}$, et al. Long-term non-pharmacological weight loss interventions for adults with type 2 diabetes mellitus. Cochrane Database Syst Rev. 2005.

21. Appel LJ, Clark JM, Yeh H-C, Wang N-Y, Coughlin JW, Daumit G, et al. Comparative effectiveness of weight-loss interventions in clinical practice. N Engl J Med. 2011;365:1959-68.

22. Chavier-Roper RG, Alick-Ortiz S, Davila-Plaza G, Morales-Quinones AG. The relationship between diabetes mellitus and body mass index primary care facility in PUERTO RICO. Bol Asoc Med P R. 2014;106:17-21.

23. Gray N, Picone G, Sloan F, Yashkin A. The relationship between BMl and onset of diabetes mellitus and its complications. South Med J. 2015;108:29-36.

24. Wang L, Liu H, Zhang S, Leng J, Liu G, Zhang C, et al. Obesity index and the risk of diabetes among Chinese women with prior gestational diabetes. Diabet Med. 2014;31:1368-77.

25. Bao W, Yeung E, Tobias DK, Hu FB, Vaag AA, Chavarro JE, et al. Long-term risk of type 2 diabetes mellitus in relation to BMI and weight change among women with a history of gestational diabetes mellitus: a prospective cohort study. Diabetologia. 2015;58:1212-9.

26. Boyle P, Boniol M, Koechlin A, Robertson C, Valentini F, Coppens K, et al. Diabetes and breast cancer risk: a meta-analysis. Br J Cancer. 2012;107:1608-17.

27. Kaaks R. Nutrition, hormones, and breast cancer: is insulin the missing link? Cancer Causes Control. 1996;7:605-25.

28. Rosner $\mathbf{W}$. The functions of corticosteroid-binding globulin and sex hormone-binding globulin: recent advances. Endocr Rev. 1990;11:80-91.

29. Plymate SR, Hoop RC, Jones RE, Matej LA. Regulation of sex hormone-binding globulin production by growth factors. Metabolism. 1990;39:967-70.

30. Suga K, Imai K, Eguchi H, Hayashi S, Higashi Y, Nakachi K. Molecular significance of excess body weight in postmenopausal breast cancer patients, in relation to expression of insulin-like growth factor I receptor and insulin-like growth factor II genes. Jpn J Cancer Res. 2001:92:127-34.

31. Oerlemans ME, van den Akker M, Schuurman AG, Kellen E, Buntinx F. A meta-analysis on depression and subsequent cancer risk. Clin Pr Epidemio Ment Heal. 2007;3:29.

32. Wakai K, Kojima M, Nishio K, Suzuki S, Niwa Y, Lin Y, et al. Psychological attitudes and risk of breast cancer in Japan: a prospective study. Cancer Causes Control. 2007:18:259-67.

33. Possel $\mathrm{P}$, Adams $\mathrm{E}$, Valentine JC. Depression as a risk factor for breast cancer: investigating methodological limitations in the literature. Cancer Causes Control. 2012;23:1223-9.

34. Wulaningsih W, Sagoo HK, Hamza M, Melvin J, Holmberg L, Garmo H, et al. Serum calcium and the risk of breast Cancer: findings from the Swedish AMORIS study and a meta-analysis of prospective studies. Int J Mol Sci. 2016;17.

35. Mourouti N, Kontogianni MD, Papavagelis C, Panagiotakos DB. Diet and breast cancer: a systematic review. Int J Food Sci Nutr. 2015;66:1-42.

36. Marques $\mathrm{O}, \mathrm{Da}$ SBM, Porto G, Lopes C. Iron homeostasis in breast cancer. Cancer Lett. 2014;347:1-14.

37. Dai J, Hu Z, Jiang Y, Shen H, Dong J, Ma H, et al. Breast cancer risk assessment with five independent genetic variants and two risk factors in Chinese women. Breast Cancer Res. 2012;14:R17.

38. Engel C, Fischer C. Breast cancer risks and risk prediction models. Breast Care. 2015;10:7-12

39. Park B, Ma SH, Shin A, Chang MC, Choi JY, Kim S, et al. Korean risk assessment model for breast cancer risk prediction. PLoS One. 2013;8: e76736.

Ready to submit your research? Choose BMC and benefit from:

- fast, convenient online submission

- thorough peer review by experienced researchers in your field

- rapid publication on acceptance

- support for research data, including large and complex data types

- gold Open Access which fosters wider collaboration and increased citations

- maximum visibility for your research: over $100 \mathrm{M}$ website views per year

At BMC, research is always in progress.

Learn more biomedcentral.com/submissions 